\title{
The Exploration to the Innovative and Entrepreneurial Talent Cultivation Path of the Application-oriented Institutes from the Perspective of General Education
}

\author{
Hui Xie \\ College of General Education \\ Heihe University \\ Heihe, China
}

\begin{abstract}
Deepening the innovative and entrepreneurial education reform of higher institutions is an innovative development strategy of the nation, an urgent need to upgrade economic system, and an important measure to promote a higher-quality employment of college graduates. General education is the hotspot of current higher education reform. With its unique educational concept adapted to the needs of the innovative talents cultivation, it plays a positive role. Therefore, how to build the mode of innovative and entrepreneurial talent cultivation in the application-oriented institutes from the perspective of general education has become the important problem to be solved. Based on the analysis of relationship between general education and the innovative talents cultivation, this paper will summarize the existing problems consisted in general education and the innovative and entrepreneurial talent cultivation, and put forward the specific path of innovative talents cultivation from the perspective of the applicationoriented institutes.
\end{abstract}

Keywords_-general education; application-oriented institutes; innovation and entrepreneurship

\section{INTRODUCTION}

The 18th Congress of China's Communist Party makes deployment to the cultivation of innovative talents, and the states put foward clear requirement to the innovative and entrepreneurial eduacation. The basic characteristics of innovative and entrepreneurial talent are creative thinking, good cognition structure and unique individual character etc., which are the specific concept, content, mode advocated by the general education. How to build a general education has become an important problem to be solved. This paper, based on the goal of talents cultivation and specifications of the application-oriented institutes, analyzes the facilitating role of general education in the perspectives of education concept, education content, teaching methods and education system, advocated by the general education. And it also explores the path to cultivating the innovative and entrepreneurial talents in

The foundation project: the article is the progressive achievement of the key project of the education science planning in Heilongjiang Province, 2015: A Research and Practice on the Training Mode of the Personnel Specialzing in Foreign Language Literature Class in Application-oriented Institutes. The project number is GJB1215047.

The foundation project: the article is the progressive achievement of the project of education and teaching reform in Heihe University, 2014: The Reseach and Practice of Talent Cultivation Mode of Classified Recruitment in the Newly-built Application-oriented Institutes. The project number is Xjg1420. the application-oriented institutes.

\section{THEORETICAL BASIS OF GENERAL EDUCATION AND THE RESEARCH OF INNOVATIVE AND ENTREPRENEURIAL TALENT TRAINING}

\section{A. The Connotation of General Education}

Concerning general education, people often have all kinds of understandings and misunderstandings. The understanding of General education connotation inevitably affect the practice of general education. General education is "liberal Study", namely, and some scholars also translate it into "liberal education". In the modern university, it is generally believed that it is Professor Byrd from American Bowdoin College who first created the phrase "general education". "General education" in Chinese is tanslated by a Taiwan scholar from the western, with references to the concept of "liberal education" and the explanation of "general" and "knowledge" in the way of Chinese traditional culture.

In fact, the idea of general education in our country sees a long history. In ancient China, the book of changes (Yi jing) requires that a "gentleman" should be learned; Zhong yong demanded that scholars should be learned, questioning, critical thinking, intellegent and actioning; Huainanzi emphasizes more on "general inteligence". Our predecessors all thought that well educated, reasonable and versatile talents can reach a state of comprehensive study.

At present, although there's no universally accepted standardization and definition of the connotation and denotation of general education, people can reach a consensus on its objectives. Professor Pang Haishao believes that general education is a historical and geographic concept with multifacets and is rich in connotation as well. Concerning present national situations, we should understand it in three dimensions: education idea, education content and talent cultivation mode. Namely, the general education is firstly a kind of education idea, focusing on how to cultivate healthy talents in spirit; secondly, it often refers to the general education content; thirdly, it means a kind of talent cultivation mode, as well, reflecting the idea and goal of general education, guaranteed by some relevant institutions. 


\section{B. The Important Role of Innovative and Entrepreneurial Talent Cultivation in the Promotion of Transformation and Development in Colleges and Universities}

In recent years, the ministry of education, the national development and reform commission, and the ministry of finance have issued documents in sequence to guide the partly ordinary colleges and universities to transfer themselves into the application-oriented institutes. During this process of transformation, we should do some deep and rational researches on "why", "what", "where", "how", and "who". Presently, our country has entered into the critical moment of accelerating transformation of the economic development mode. And the economic development turns into a new normal state. Innovative and entrepreneurial education is a kind of new mode arising at the historic moment in the process of economic and social development, serving as an effective carrier to realize "public entrepreneurship and innovation". It not only promotes the reform of the education and teaching in colleges and universities, but also provides an effective way for the sustainable development of colleges and universities.

\section{Analysis on the Relationship Between General Education and the Cultivation of the Innovative and Entrepreneurial Talent}

Innovation is the soul of a nation's progress, and the innovative and entrepreneurial education is a kind of teaching concept and mode, adapted to the necessities of economic society and national development. General education plays a very important role in the acquirement of the students' knowledge, the improvement of their learning ability, humanistic quality, social adaptability and the promotion of their comprehensive development. And these qualities of open ideas, broad vision, good humanities, mature psychological quality and rich individual ability are the necessities of innovative and entrepreneurial talents. However, it is difficult to achieve these qualities through a single professional education except general education. Firstly, general education is helpful to build a reasonable knowledge structure of college students. Secondly, the general education promotes the comprehensive development of innovative and entrepreneurial talents. Thirdly, general education is helpful to the formation of good characters of innovative talents. Fourthly, the general education creates a relaxing environment for innovative and entrepreneurial talents. Finally, general education pays much attention to carrying out extracurricular activities and helps to cultivate students' practical and manipulative ability.

\section{Challenges AND EXISTING PROBLEMS In THE GENERAL EDUCATION AND CULTIVATION OF INNOVATIVE AND ENTREPRENEURIAL TALENTS}

\section{A. The Challenge of the General Education}

General education is popularized in many countries and regions of the world, and it is true that its concept and value are gradually accepted by more and more universities. However, there are still some challenges. The greatest challenge is that as higher education scale continues to expand, more and more people consider the higher education a way of preparing for the future career, and the university as a vocational training place. Such personal utilitarian pursuit is intensified in the environment of long-term economic recession. And some colleges and universities tend to be more conducive to provide students with employment education and curriculums so as to meet their demands as a consumer.

In China, there exist many problems and challenges in promoting the general education. For the external environment, the social expectations of higher education become higher and higher. And a lot of people consider general education as a luxury and they don't believe in general education due to their pursuit of narrow utilitarianism, employment and career. While, from the inside of the university, general education ideas seem to be universally affirmated, but there arises all sorts of questions, even resistance and rejection in the specific implementation. Obviously, this is associated with the positioning and design of general education in the university. Yet, this contradictory phenomenon does not only exist in the mainland universities. Jin Yaoji, previous president of the Chinese University of Hong Kong, pointed out, "general education in contemporary university meets a kind of contradictions and difficulties. On the one hand, the importance of general education has been continuously affirmed in concept, and on the other hand, the importance of general education has been diluted, even ignored in practice. So these contradictions and difficulties are mainly the problems of determinateness and positioning of general education". Since the nature and the goal of talent cultivation in each university are definitely different, we should make great lenghth to set up the teaching goals and system of general education, according to the reality of each university.

\section{B. The Existing Problems in General Education and the} Cultivation of Innovative and Entrepreneurial Talents

1) Ineffectiveness of general education management system: Scientific and effective management plays an important role in promoting the implementation of general education. Most application-oriented institutes can not manage the general education maturely, and do not make sense of the connotation of general education, talent cultivation target and mode, and even never make a plan for it in the long run. Inside the school, there are no specialized management institutions, which causes a loose situation. As a result, nobody is responsible for teaching implementation and evaluation affairs. And the students are in a blind state, without guidance when choosing their subjects. The setting of general education curriculum is arbitrary, without a unified guidance. There is neither strict standard for the quality of general education, nor established teaching quality assessment, or monitoring system.

2) Flaws of the settings of the general education curriculum: The course is an effective carrier of the implementation of general education. General education shoulders the lofty mission of cultivating all-round developped talents. General education also means to cultivate students' knowledge structure, basic skills, elegant temperament, perfect personality and the perfect human nature. What kind of courses can achieve such effect? This 
undoubtedly increases the difficulties of the setting of general education curriculums. Presently, the application-oriented institutes set so many compulsory courses that they can but set up general elective courses in order to develop the socalled general education. As a result, cultural courses are in small portion and lack of unsystematicmness. Therefore, these courses cannot integrate with each other, and are lack of logics, which makes the general education superficial and formalized.

3) The lack of teachers for general education curriculums: "Teachers" is the most important element in teaching. To implement the idea of general education, the "teachers" is one of the most important factors. At present, in the applicationoriented institutes, teachers with both knowledge of science and art are in a small number. Courses are usually taught by relevant professional teachers. However, different teachers will bring different effects on the students when they hold different teaching ideas. The ones who are knowledgeable, with flexible teaching methods and the ones who disregard for general education, with narrow range of knowledge and monotonous teaching methods will definitely bring contradictory effects. In addition, college teachers with the pressure of the scientific research, prefer undertaking their specialized courses to teaching these "warming-up" curriculums of general education.

4) The lack of innovative and entrepreneurial education concept: Scientific education concept is the endogenetic force of the progress of higher education. At the present stage, people are indifferent to the concept of innovative and entrepreneurial education concept, and they don't really make the idea deeply rooted in their hearts. People misunderstand the connonation of innovative and entrepreneurial education, they think it a way of alleviating employment pressure. There is no specialized management and research department in most of the application-oriented institutes temporarily. And it is the teachers from the student management department, the department of employment guidance, youth corps committee, or the ideological and political research department who teach these courses of general education and organize the related activities. Furthermore, it is the leaders resposible for the student affairs rather than teaching affairs who take charge of the innovative and entrepreneurial education. All in all, these messy management situation hasn't been disentangled, which makes it difficult to conduct ligitudinal education due to the lack of links between innovative and entrepreneurial education and subject teaching.

5) Staying superficial of innovative and entrepreneurial education: The State Council and the Ministry of Education attach great importance to the reform of innovative and entrepreneurial education in colleges and universities, and have issued documents with clear requirements continuously. Since 2015, the Ministry of Education has comprehensively deepen the education reform, aiming at 9 tasks of reformation, and has taken more than 30 specific measures in all colleges and universities. In the ducuments, these compulsory and elective courses of general education are to be available to all students and to be incorporated into the credit management. At present, the innovative and entrepreneurial education in most of the application-oriented institutes is spread in the form of elective courses, extracurricular activities, lectures, competition or entrepreneurial policy guidance, a small business loan consulting, entrepreneurial start-up procedure and so on. Most of them stay at the operating level, without teaching content or knowledge system, and do not integrate with the talent cultivation system in the universities.

\section{The SPECIFIC PATH TO INNOVATIVE AND ENTREPRENEURIAL TALENT CULTIVATION IN THE APPLICATION-ORIENTED INSTITUTES}

\section{A. Practising General Education Idea, and Positioning Innovative and Entrepreneurial Education Clearly}

Application-oriented institutes should further enhance the understanding of the general education connotation and its significance. The concept of general education is so concrete and vivid that it should be the spirit, individual character and quality of a school, reflecting its understanding and pursuit of talent training. Application-oriented institutes should actively comply with the new trend of "public entrepreneurship and innovation", firmly grasping the new opportunity of the transformation of application-oriented institutes, by the guidance of differential development strategy. We should also summarize the connotation of the innovative and entrepreneurial education idea, and make clear of the purpose of it, relying on the teaching reform and management innovation. In this way, the general education goes through the whole process of talent training.

\section{B. Reforming Teaching Content, and Setting the General Education Curriculum Reasonably}

The broad and subtle knowledge structure of the educatees is the necessary quality of innovative talents. It is the premise and foundation for them to do some innovative and entrepreneurial researches. The importance should be attached to the interdisciplinary, professional and comprehensive courses, in order to motivate students to integrate science with arts, and make efforts to expand their professional basis and enhance the general education. To establish a scientific and reasonable curriculum system is the core to strengthen general education, to improve college students' humanities and innovative consciousness and abilities. As a rusult, we should break the barriers between disciplines, build a batch of crossed, comprehensive general curriculum resources, and promote the humanities and the mastery of scientific knowledge. Education should not only emphasize on the fundamental and comprehensive curriculum contents, but also emphasize the system on its integration and penetration. At the same time, general and professional education should be organically integrated with each other, so as to form the curriculum system of general education with its unique characteristics. 


\section{Improving Teachers' Ideological Understanding, and Establishing the Teachers' Guarantee System}

Factors such as teachers' quality, consciousness, enthusiasm are relevant to the implementation of general education and the cultivation of innovative and entrepreneurial talents.

Teachers' attitude and participation decide whether the cultivation of innovative and entrepreneurial talent will be successful or not. Above all, the teachers' cognition of general education and innovative and entrepreneurial talents cultivations should be strengthened. In the second place, an active, heathy and upward air of general education and innovative and entrepreneurial talent cultivation should be created. And we should integrate these concepts into all the curriculums in the universities and enrich teachers' knowledge structure as well. Thirdly, professional teachers' team shoulde be established. Teachers should be organized to participate in the international and domestic project academic conferences regularly, so as to learn more extensively related teaching knowledge. And a general and professional related teachers' team, mainly engaged in the general education should be established and carry out the local characteristics of innovative and entrepreneurial education research. Finally, innovative entrepreneurial practice teachers team should be set up, and experts in innovative and entrepreneurial education could be employed as part-time teachers to make up for the lack of specialized teachers in the application-oriented institutes.

\section{Improving the Monitoring System, and Enhancing the Teaching Quality Continuously}

Effective teaching evaluation and monitoring are the basic and defensive line of improving the teaching quality, which cannot be slackened. First of all, multi-level evaluation system should be set up by the government, media, intermediary institutions and scholars to evaluate the innovative and entrepreneurial education condition. To follow the requirements and quality standards of the general education and innovative and entrepreneurial talent training, we should make teaching plans, curriculum outline, curriculum organization and curriculum evaluation, according to the talent cultivating program, and then accomplish regular management. Secondly, we should implement a regular teaching management. The normalization of observing-andcommenting lesson can be achieved. And teaching quality evaluation can be achieved in the way of collecting comments from the peer teachers, online appraisal, feedback interviews, and questionnaire survey from the students, according to the teaching quality evaluation criteria. Finally, the working mechanism of quality evaluation should be established. The way of evaluation affects the accuracy and authenticity of the results, therefore, we have to ensure that the investigation statistics are comprehensive and effective. At the same time, do not confuse the evaluation subject and evaluation standards, and effectively meet the demands of multi-level and diversified evaluation subjects.

\section{REFERENCES}

[1] Chen Xiangming. The Differentiation and Analysis of the Concept of General Education [J]. Journal of Higher Education, 2006, (3).

[2] Li Jiamei. Concerning the Role of General Education in Cultivation of the Employment Competitiveness [J]. Journal of Heilongjiang Local Chronicles, 2012, (23).

[3] Qin Shaode. The Understanding and Practice of General Education in Fudan [J]. Higher Education in China, 2006, (15).

[4] Sun Hua. The Situation of General Education in China[J]. Journal of Higher Education in Jiangsu Province, 2013, (3).

[5] Lei ZhiYi. On the General Education and the Cultivation of Innovative Talent [J]. Science Tribune, 2012, (9).

[6] Ru Ning, Shen Yaping. Three Designing Principles of the Curriculum System of Entrepreneurial Education $[\mathrm{J}]$. Journal of Teaching in Chinese University, 2013, (7). 